\title{
Performance-Based Assessment: Approach and Obstacles by Higher-Elementary Science Teachers in Palestine
}

\author{
Marwan M. A. Abualrob ${ }^{1} \&$ Said H. Al-Saadi ${ }^{2}$ \\ ${ }^{1}$ Department of Elementary Education, Arab American University, Palestine \\ ${ }^{2}$ English Language Department, Mazoon College, Sultanate of Oman \\ Correspondence: Marwan M. A. Abualrob, Elementary Education Department, Faculty of Arts, Arab American \\ University, P. O. BOX 240, Jenin-West Bank, Palestine. E-mail: marwan.abualrob@aaup.edu
}

\author{
Received: January 26, 2019 Accepted: February 27, $2019 \quad$ Online Published: March 6, 2019 \\ doi:10.5539/jel.v8n2p198 URL: https://doi.org/10.5539/jel.v8n2p198
}

\begin{abstract}
The study sought to identify the extent to which higher-elementary science teachers utilize the Performance-Based Assessment Approach. It further aimed at investigating the factors that hinder science teachers from using performance-based assessment in Palestine. The study data were collected by questionnaire administrated to 109 science teachers from 60 higher elementary schools. Semi-structured individual interviews were conducted with 14 science teachers. The findings indicate that Palestinian science teachers rarely utilize Performance-Based Assessment to assess their students' achievement. It was concluded that the selected science teachers have obstacles in implementing Performance-Based Assessment which was grouped into five categories. Recommendations were offered in light of the study findings.
\end{abstract}

Keywords: performance-based assessment, higher elementary, science teaching, obstacles, approach

\section{Introduction}

Continuous assessment of students' learning is an essential aspect of successful teaching. Effective teaching involves the use of different assessment strategies to diagnose students' strengths as well as needs, to plan for teaching and to provide feedback to students and parents concerning achievements. Therefore, the primary purpose of classroom assessment is to facilitate learning rather than sorting or labeling students.

Traditionally, teachers used to rely on pencil-and-paper evaluation. However, recent researchers like Colley (2008) contradict this practice saying that such assessments do not always reveal what students really know. They argue such usual approach of traditional assessments does not capture the extent to which learners have acquired the required understanding of a topic nor if they have mastered complex skills like critical thinking or problem solving (Amrein \& Berliner, 2002; Herrera, Murry, \& Cabral, 2013; Volante, 2004). These kinds of evaluations do not always reveal what the students really know. Therefore, "teaching to the test" has become a common practice in schools (Izard, 2004; Resnick, 1996), narrowing students' potential to low-level skills. In addition, science educators claim that traditional tests cannot sufficiently evaluate students' ability to design and undertake experiments or assess their understanding of scientific concepts (Whitman, Klagholz, Schechter, Doolan, \& Marganoff, 1998). In fact, Saadi (2009), Espinosa (2015) and Taylor (2006) claim that these tests cause high levels of anxiety and lead to losing interest in learning.

This has created the need to call for assessment strategy reforms that assess students on scientific reasoning and understanding rather than simply measuring discrete knowledge. Therefore, critical assessment methods were developed, with a preference for performance-based assessment (PBA) (Morrison, McDuffie, \& Akerson, 2003; Scott, 2002). Researchers such as Hakel (1998) and Howell, Brocato, Patterson, and Bridges (1999) identify performance-based assessment as the focus for education reforms in assessment, curriculum, and instruction. The proponents for this type of assessment claim that PBA is more motivating to students. They provide a model for what teachers should be teaching and students should be learning. PBAs constitute a complex, extended performance (Baron, 1991) that allow for evaluation of both process and product (Messick, 1994). Moreover, performance-based tasks provide more direct measures of student abilities than multiple-choice items (Lai, 2011). They are able to assess students' knowledge and skills at deeper levels than traditional assessment approaches 
and are better suited to measuring certain skill types, such as report writing and critical thinking (Frederiksen, 1984).

PBA also improves student skills by bringing into play complex functions of cognitive processing that require a higher level of thinking for problem-solving, or the development of options when an individual confronts a new situation (Espinosa, 2015).

Performance-based assessments as described by Stiggins (2001) is a set of strategies that enable students to use their skills and knowledge to perform a task that is authentic and realistic based on certain predetermined criteria. PBAs measure students' achievements by involving them in real and authentic situations through tasks that operate as educational activities in which students practice higher-level thinking skills, and adapt plenty of knowledge in order to make decisions and solve real-life problems. This can be the rationale behind that many decision makers are requiring performance-based assessment in the different sectors of education, including science education. Glisan and Adair-Hauck (2007) justify such new assessment trend because PBA is practical tools that can be used to improve education and positively impact learners and instructors.

This study is motivated by recent research findings showing that Palestinian teachers tend to be traditional in their assessment techniques. Diab (2005) discussed the finding that Palestinian science teachers focus on memorization and rely on lower-level cognitive goals. In addition, they are limited in their understanding of how to use achievement tests to evaluate the performance of their students. This accordingly makes the evaluation process unable to provide sufficient information to educators as well as parents about the students' actual progress.

2003, 2007, 2011 outcomes of the Trends in International Mathematics and Science Study (TIMSS) showed that Palestine students achieved alarming results in science and mathematics when compared to other countries. Palestine was ranked 34 among 47 participating countries in 2003, 43 among 49 participating countries in 2007, and 35 among 42 participating countries in 2011 (Palestinian Ministry of Education and Higher Education, 2011). The internal association for evaluating students' educational achievement classification in 2013 has announced that only $1 \%$ of Palestinian students have achieved the internal advance level in science. Abed (2014) concludes that the assessment practices for the participating Palestinian science teachers and the classroom discussions that happened in their classes were focusing on lower-order thinking skills which are memorizing, comprehension and direct application. The focus on higher-order thinking skills such as analysis, synthesize, and evaluation was little especially in the lower performing schools.

Odeh (2015) highlights the importance of developing the assessment tools used in Palestinian schools and the necessity of using performance-based assessment tools that address higher-order thinking skills. In addition, he indicated the necessity to train science teachers to employ higher-order thinking skills in their teaching and assessment practices. The current study tries to explore the extent to which science teachers apply the strategies of performance-based assessment and as well as to investigate the factors that hinder the use of performance-based assessment approach by higher elementary science teachers in Palestine.

\subsection{Research Questions}

This study was guided by the following research questions (add :)

1) To what degreed do higher elementary science teachers use performance-based assessment strategies in Palestine?

2) To what degree do higher elementary science teachers use performance-based assessment tools in Palestine?

3) What are the factors that hinder higher elementary science teachers in Palestine from using performance-based assessment strategy?

\section{Methodology}

Triangulation of data collection techniques is considered crucial factors in this study therefore; varieties of data were gathered and compared using multiple methods such as questionnaires, and interviews.

\subsection{Participants}

The population of this study consists of all the higher elementary science teachers from fifth to tenth classes belonging to the directions of education in Jenin, Qabatyah, Toubas for the academic year 2016/2017. A random sampling technique was used to select 144 science teachers teaching science in grades 9 and 10 schools from 60 schools. They consisted of 130 teachers targeted by questionnaires 109 found to be useful for analysis and personal interviews were held with 14 other science teachers. 
The total number of questionnaires that were found to be useful for analysis is 109 distributed in the next table according to gender, years of experience and background about PBA.

Table 1. Questionnaire participants according to gender and years of experience

\begin{tabular}{llllll}
\hline & Gender & \multicolumn{4}{l}{ Years of Experience } \\
\cline { 2 - 6 } & male & female & $(1-5)$ years & $(6-10)$ years & $(11-$ up $)$ years \\
\cline { 2 - 6 } Total & 41 & 68 & 21 & 32 & 56 \\
\hline
\end{tabular}

Table 2. Questionnaire participants according to educational background and background about PBA

\begin{tabular}{llllll}
\hline & \multicolumn{2}{l}{ Educational Background } & & \multicolumn{2}{l}{ Have taken a course on PBA } \\
\cline { 2 - 6 } & diploma & bachelor & master & yes & no \\
\cline { 2 - 6 } Total & 14 & 87 & 8 & 64 & 45 \\
\hline
\end{tabular}

It is important to understand that all schools adopt the same science program. In other words, they have the same course books, assessment style, resources, and so forth. The students in all selected schools share the same background characteristics. They are, for example, Palestine, boys, and girl, aged between 15 to 17 years, in grade 10. Each of the schools can represent the others in terms of philosophy, contents, objectives, needs, students, and teachers.

\subsection{Instruments}

The current study used questionnaires to collect information from science teachers in Palestine public schools. Questionnaires are widely used in educational researches as a technique to identify attitudes and perceptions (Kaewpet, 2009; Krohn, 2008; Read, 2008). The science teachers' survey was written in Arabic, for two reasons. First, it was easier for teachers to understand in their native language. Second, the statements included were difficult and responding to them in English might make it more complex for teachers to fully grasp the intent of the survey.

The questionnaire, entitled Using Performance-Based Assessment Approach by Higher-Elementary Science Teachers in Palestine scale, was developed based on Al-Basher and Barham (2009) and Zoubi (2013).

The students' questionnaires consisted of three sections. Section one collected the demographic information about teachers and students. It is worth saying that the personal information like gender, qualification and years of experience were not considered as study variables rather they provided information about whether the questionnaires were distributed to a sufficiently varied sample to represent the study population. Section two included the teachers' perceptions about Using Performance-Based Assessment Approach by Higher-Elementary Science Teachers in Palestine. These data were based on the 5-points Likert self-report scale on the type and frequency of usage of the assessment that the teachers practice.

The researchers, by using interviews, has the advantage of clarifying and disambiguating unclear questions in the interview due to in-depth coverage of the issues. The information gained from these interviews was used for triangulating the data gathered from the questionnaires with the researchers' interpretation of that data by having teachers talk about their perception.

The researchers visited the schools and interviewed 14 teachers. In the interviews, the teachers were asked about using performance-based assessment strategy and using actual rating approaches in evaluation system and what are the factors that limit to using performance-based assessment approach by higher elementary science teachers in Palestine. The interviews were audio-recorded, transcribed, and qualitative data were analyzed according to the constant comparative method.

\subsection{Data Analysis}

As to the questionnaires, descriptive statistics were used to answer the research questions by implementing the SPSS software. The descriptive statistics were used to indicate the percentage and frequency distribution of the respondents' answers. Measures of central tendencies (mean and standard deviation) were used to analyze the data for the research questions 1-2. Interview data were analyzed by a close study of the transcripts to identify what interviewees say about their attitudes and perceptions about the use of performance-based assessment by higher-elementary science teachers in Palestine. After conducting the interviews, the analysis started with their 
transcription from the audio cassettes. Finally, content analysis as a systematic and objective research method was used in collecting data for research question three.

\section{Findings and Discussion}

In what follows, the findings are organized according to the research questions.

\subsection{Findings of the First Research Question}

The second section of the teachers' questionnaire elicited data on how often science teachers use each strategy of performance-based assessment and classical (traditional) assessment. Teachers were provided with 25 different strategies of PBA and classical (traditional) assessment and asked to choose from five-point scale rank (always = 5 , often $=4$, sometimes $=3$, rarely $=2$, never $=1$ ). The participants' answers were analyzed using the mean and standard deviation of each statement. Then they were arranged in a descending order to provide a clearer picture of the overall use of performance-based assessment strategy.

Table 3. Means and standard deviation of the use of performance-based assessment strategie

\begin{tabular}{lllll}
\hline $\mathrm{N}$ & PBA strategy & means & Standard deviation & How often \\
\hline 11 & Assessment based on end-of-term tests & 4.46 & .646 & often \\
6 & Assessment based on paper and pen (tests) & 4.40 & .759 & often \\
10 & Assessment based on monthly tests & 4.21 & .809 & often \\
9 & Assessment based on unit end tests & 4.13 & .886 & often \\
8 & Assessment based on short tests & 3.95 & .832 & sometimes \\
17 & Assessment based on laboratory reports & 3.93 & .993 & sometimes \\
2 & The assessment based on the clarification, as if presenting a concept & 3.47 & 1.118 & sometimes \\
& through a practical experience or linking it to reality & & & sometimes \\
5 & Assessment based on discussion and debate & 3.41 & 1.187 & sometimes \\
7 & Assessment based on working papers & 3.25 & .927 & sometimes \\
3 & Assessment based on talk, such as talking about a film seen or a trip & 3.20 & 1.21 & sometimes \\
1 & Assessment based on presentation & 3.07 & 1.03 & rarely \\
4 & Assessment based on simulation and role play & 2.95 & .906 & rarely \\
23 & Assessment based on the student's diary & 2.94 & 1.161 & rarely \\
22 & Assessment based on using devices & 2.88 & 1.021 & rarely \\
25 & Assessment based on observation & 2.82 & 1.231 & rarely \\
13 & Assessment based on group work & 2.82 & .965 & rarely \\
18 & Assessment based on student performance records & 2.74 & 1.149 & rarely \\
15 & Project-based assessment & 2.74 & 1.003 & rarely \\
19 & Assessment based on producing a model & 2.74 & 1.057 & rarely \\
12 & Assessment based on the interview & 2.69 & .937 & rarely \\
24 & Assessment based on open tasks & 2.62 & 1.144 & rarely \\
21 & Assessment based on collecting things from environment that related to the & 2.61 & .999 & rarely \\
16 & science lesson. & & & rarely \\
14 & Assessment based on research papers & 2.60 & .933 & rarely \\
20 & Assessment based on designing a computer program & 2.57 & 1.082 & 2.56 \\
\hline
\end{tabular}

The first part of the questionnaire provided the teachers with 25 assessment strategies, 20 strategies reflected the performance-based assessment strategies and the remaining 5 items are classical or traditional assessment strategies. The findings show that the highest five means after the statistical analysis ranging from 4.46 to 3.95 were items $(11,6,10,9,8)$ representing assessment based on end-of-term tests, paper and pen (tests), and the monthly tests, unit end tests, and short tests. This suggests that the participants are test-oriented teachers as they heavily depend on exams for students' evaluation. This indicates that marks or degrees are still the prime references for students' evaluation. This can be attributed to the fact that they don't have sufficient time to use the strategies of performance-based assessment due to the high teaching load and insufficient training or practice for the use of alternative assessment strategies. This finding comes in line with Airasian (2005) finding that teachers are more oriented to use pen and paper test. It is easier for them to have hard documentation to be used for administrative referencing. Mueller (2012) on the other hand admits that a teacher should not only choose either way but should have a mixture of them to help him meet the students' needs. 
The most used performance-based assessment strategy is laboratory reports (item 17). Such an assessment is part of the formal assessment element that students have to submit during the semester; therefore, teachers have the tendency to practice it to fulfill the evaluation procedure adopted by the ministry.

The most rarely used strategies are as in item $(24,21,16,14,20)$ which represent the assessment based on open tasks, collecting things from the environment that related to the science lesson, research papers, the student portfolio (file of achievement), and designing a computer program. It is clear that such stratagems require more time and efforts by students and teachers. In addition, these tasks are not familiar to the students and teachers as they are not part of the alternative assessment policy issued by the MOE.

Overall, PBA strategies obtained a weak means average which indicates that they are rarely used by the targeted science teachers. This can be justified by the first part of the above table especially items $(11,6,10,9,8)$ which suggest that the participants are test-oriented teachers as they heavily depend on exams or formal tests for students' evaluation. This finding is also supported by Ohlsen (2007) who found that the classical assessment of such exams was highly used by $80 \%$ of the teachers. Cheng (2006) also found out that teachers depend on the classical assessment and there was a need to train teachers on the use of alternative assessment procedures. Other researchers like Allawnah (2007) and Almdlal (2000) concluded that written exams are the most common among teachers.

Findings of the first research questions show that Palestine science teachers depend on the classical testing approach to assess students learning. They are not motivated to make use of alternative assessment strategies like PBA. Exams can provide some vision of the students' conceptual development, but no evidence of their competence improvement. One goal of a performance assessment is to judge the level of competency students achieve in science, therefore; performance assessments can produce useful information regarding the extent to which students gain the skill and knowledge as well as create the need to train teachers on how best they can make use of PBA.

\subsection{Findings of the Second Research Question}

The third section of the teachers' questionnaire elicited data on how often do science teachers use alternative assessment tools. Teachers were provided with 5 different assessment tools and asked to choose from five-point scale rank (always $=5$, often $=4$, sometimes $=3$, rarely $=2$, never $=1$ ). The participants' answers were analyzed using the mean and standard deviation of each statement.

Table 4. Means and standard deviation for the use ofthe assessment tools

\begin{tabular}{llll}
\hline $\mathrm{N}$ & Assessment tools & Means & Standard deviation \\
\hline 26 & Checklist & 2.8624 & 1.18218 \\
27 & Rubric & 2.7982 & 1.09527 \\
28 & Rating Scale & 2.6422 & 1.01400 \\
29 & learning log & 2.1743 & 1.36656 \\
30 & Anecdotal Record & 1.9358 & .98390 \\
\hline
\end{tabular}

Analyzing Palestinian science teachers' use of the alternative assessment shows that majority of the teachers rarely use performance-based assessment tools. The checklist has obtained the highest means average (2.86) among the other tools. This conclusion is supported by the findings of other research questions in the current study as in finding the first and third research question. Teachers rarely utilize performance-based assessment rather they heavily depend on tools of classical assessment as they don't have the experience to use tools of performance-based assessment. This is compatible with the results of Table 1 which emphasizes teachers' reluctance to apply performance-based assessment strategies.

\subsection{Findings of the Third Research Question}

To answer the third research question, the teachers were interviewed by the researchers to provide more in-depth insight regarding the purposes and the obstacles that hinder them from using performance-based assessment in classrooms. The interviews with the 14 teachers were analyzed according to five main categories that emerged from the teachers' answers. Each case summarizes a representative quote from one or two teachers, which reflects the teachers' views. 


\subsubsection{Knowledge of Performance-Based Assessment Approach}

By trying to examine the respondents' understanding of the PBA, the researchers noticed that not all participants had the clear understanding of PBA A teacher commented on this by saying, "I do not know if the performance-based assessment is different from the usual assessment practice we do daily." This finding provided a justification for why teachers rarely used some assessment strategies as found in the first part of this study found.

Many teachers pointed to not have enough knowledge of this kind of assessment. When we asked about the meaning of it, only one person answered correctly. Many were confused between Performance-Based Assessment and tradition assessment strategies and tools. Another teacher explained, "Performance-Based Assessment relays on student and gives space to the teacher for diversification in questions".

The most dominant tool used by the participants tested. This was concluded by a teacher who said: "tests are the only real tool that you can vary in questions". This created the demand to train teachers on PB assessment by explaining its tools and strategies theoretical and practical.

\subsubsection{The Work Assigned to the Science Teacher}

Explaining the reasons for not updating themselves with the new assessment's strategies, teachers argued that they rarely have time to do so. The amounts of duties assigned to them hinder them from adapting PBA strategies. One teacher put it:

"You want me to design tools or cooperate in designing tools with my colleagues, then evaluate my students on every activity. It's impossible because there are many writing works that I should complete during this year".

The total number of periods during the week is another factor according to teachers' perceptions that hinder them from applying PBA. One teacher describes that "The required work is more, the number of classes is 24 in the week, the rotation is twice in a week, participating in school committees.... etc."

\subsubsection{Congestion Classroom}

Six teachers confirm that the students' number in a classroom doesn't allow making activities and adopting modern assessment strategies. Some teachers said, "I have 39 students so how I can follow every student and apply real assessment strategies for them". Another teacher thinks that "It's not possible to follow and assess 40 students by verbal appreciation scale ...."

Teachers say that they do not have the freedom to choose or apply any assessment tools that are not listed in the approved Ministry of Education assessment document. All teachers confirm it is not possible to follow PBA as an alternative type of evaluation under the current assessment policy that is imposed by the MOE. There is a midterm, final, and four daily exams that the teacher should do on time. A teacher highlights that "I am asked to do exams and put marks on time so the system doesn't allow changes and modification" "How can I follow this type under daily, midterm, and final exams that I have to them?"

The system is exam-oriented according to the teachers' perceptions. The teachers can only respond to the OE evaluation policy that emphasizes the use of tests. One teacher describes the practice by saying "They don't allow to us using performance-based assessment strategies. They allow the only exam. Or we will face investigation." Another teacher said, "There is a keen control on examinations and pledge in conducting daily exam, then midterm, daily, and final during the semester."

\subsubsection{Curriculum}

All teachers confirm school books are designed in a way that prevents them from using different assessment strategies. This is another crucial factor for not being able to use the PBA, the way course books are designed according to the teacher in a way that does not promote the use of performance-based assessment. One teacher describes that "If you look at the assessment system in science books, you will see the books are questions at the end of lessons, chapters, and units". It meant that no tasks are designed in the syllabuses that assess students learning by PBA strategy. "Required performance and product actions from students are few and they are found in the form of educational activities, not evaluation".

Five teachers confirm that they are teaching for the exam, so their focus is on how their students get higher marks. A teacher elaborates that "The important thing for me; how my students get the higher marks in ministerial exam, therefore, I care examinations, not their product and performance." While another teacher said that "My student results are seen by the director, the ministry, and parents in students' examinations, not their performance". 
The discrepancies in the participants' understanding about the purpose of the EL program in Grade 11 was because the objectives and the curriculum framework of the whole program were not available to them, which made them, understand the purpose in their own way.

\section{Conclusions}

To enhance the teaching processes and create reflective teachers, it is always recommended to cohesively revise what teachers do to develop and improve the teaching and assessment strategies they adopted in classrooms. That is an underlying attempt of this paper which to direct teachers' professional practice to help them update and enhance their teaching and assessment practice as educators. As teachers, they need to equip themselves with varieties of teaching and assessment strategies and techniques to teach and assess our students appropriately. Therefore, it has become an important element of teachers' professional programs to be up-to-date with current educational research trends on best practices for assessment in order to provide them the support they need to be effective and reflective teachers.

Obviously, many secondary schools around the world, including Palestine, continue to focus only on classical or traditional assessment strategies like pen and paper tests. That needs to be changed. It is time to use authentic assessments such as performance-based assessments as called by many scholars like Espinosa (2015). Such assessment considered to be more pontifical for students as they provide them to be active participants in the education processes. Teachers need to create opportunities for students to demonstrate their skills as well as knowledge as rewards for their learning progress instead of highlighting what they cannot do. They have to diagnose learning and teaching problems and focus on the continuous improvement of each learner which will lead, in the end, to the students' success.

The obtained results show that the study sample is test-oriented teachers as they heavily depend on exams for students' evaluation. In addition, PBA is rarely used by the targeted science teachers. This, however, contradicts with the call for the implementation of more effective assessment strategy like PBA. Therefore, more comprehensive study is recommended to provide a nationwide analysis of the obstacle hindering Palestinian science teachers from making use of PBA to enhance their students learning outcomes.

The science learning and teaching have to be reformed in the way that teaching emphasizes the role of task or skill acquisition rather than only knowledge transfer. To teach science in these ways, teachers need to move away from traditional models of assessment that emphasize memorizing facts and covering a large number of discrete topics, focusing instead on performance-based assessment. MOE, therefore, should establish professional development programs for school science teachers where they would have adequately rigorous opportunities to engage in effective science assessment practice like training them on how best they can utilize the less used PBA tools as in findings of Table 4.

Another practical or empirical consideration of this study is that the heightened obstacles in the finding of the third research question hindering science teachers from using PBA require further study. More in-depth studies are required to understand the effect of classroom size, workload, and knowledge of PBA on science teachers use of PBA.

\section{References}

Abed, S. (2014). A Descriptive Study of the Role of Assessment Instruments in Developing Eighth Grade Students' High Cognitive Skills in Science. Unpublished Master thesis, Birzeit University, Palestine.

Airasian, P. (2005). Classroom Assessment: Concepts and Applications (5th ed.). Boston, MA: McGraw- Hill.

Al-Basher, A., \& Barham, A. (2009). Using Alternative Assessment Strategies in Assessing Students' Learning in Mathematics and Arabic in Jordan. Hashemite University. Retrieved from https://eis.hu.edu.jo/deanshipfiles/pub103762158.pdf

Allawnah, H. (2007). Science Teachers Practices for the Alternative Evaluation Techniques in Teaching Science in 8th Basic Grade in Jordan and Their Difficulties. Unpublished Master thesis, Yarmouk University, Jordan.

Almdlal, B. (2002). Methods and Using Performance-Based-Assessment for Biology to 9th and 10th Grades according to Point of View of Biology Teachers. Unpublished Master thesis, An-Najah National University, Palestine.

Al-Saadi, S. (2008). Effective Evaluating of Students' Writing: An Applied Perspective. Professional and Academic English IATEFL, 31, 59-62. University of Kent, Canterbury, UK.

Amrein, A., \& Berliner, D. (2002). High-stakes testing, uncertainty, and student learning. Education Policy Analysis Archives, 10(18), 1-69. 
Baron, J. B. (1991). Strategies for the development of effective performance exercises. Applied Measurement in Education, 4(4), 305-318. https://doi.org/10.1207/s15324818ame0404_4

Colley, K. (2008). Performance-based assessment. Science Teacher, 75(8), 68-72.

Cheng, H. (2006). Junior secondary science teachers understanding and practice of alternative assessment in Hong Kong: implication for teacher professional development. Canadian Journal of Science Mathematics and Technology Education, 6(3), 227-243. https://doi.org/10.1080/14926150609556699

Diab, M. (2005). The Impact of the using Portfolios in the Development of Science Thinking and Retention for Grade Students. Unpublished Master thesis, Islamic University, Gaza, Palestine.

Espinosa, L. F. (2015). Effective Use of Performance-based Assessments to Identify English Knowledge and Skills of EFL Students in Ecuador. Theory and Practice in Language Studies, 5(12), 2441-2447. https://doi.org/10.17507/tpls.0512.02

Frederiksen, J. R. (1984). The real test bias: Influences of testing on teaching and learning. American Psychologist, 39, 193-202. https://doi.org/10.1037/0003-066X.39.3.193

Glisan, E., Uribe, D., \& Adair-Hauck, B. (2007). Research on integrated performance assessment at the post-secondary level: Student performance across the modes of communication. Canadian Modern Language Review, 64(1), 39-67. https://doi.org/10.3138/cmlr.64.1.039

Hakel, M. D. (1998). Beyond multiple choice: evaluating alternatives to traditional testing for selection. Mahwah: Lawrence Erlbaum Associates.

Herrera, S. G., Murry, K., \& Cabral, R. M., (2013). Assessment accommodations for classroom teachers of culturally and linguistically diverse students (2nd ed.). Boston, MA: Allyn \& Bacon.

Howell, L., Brocato, D., Patterson, K., \& Bridges, T. (1999). An evaluation of performance task instruction in the classroom. (ERIC Document Reproduction Service No. 435761)

Izard, J. (2004). Gathering evidence for learning. Paper presented at the Annule Conference of the Australian Association for Research in Education (AARE) Melbourne.

Kaewpet, C. (2009). Communication needs of Thai civil engineering students. English for Specific Purposes, 28 , 266-278. https://doi.org/10.1016/j.esp.2009.05.002

Krohn, N. (2008). The Hebrew language needs of Rabbinical students in the conservative movement. Unpublished $\mathrm{PhD}$ thesis, Columbia University, USA.

Messick, S. (1994). The interplay of evidence and consequences in the validation of performance assessments. Educational Researcher, 23(2), 13-23. https://doi.org/10.3102/0013189X023002013

Morrison, J., McDuffie, A., \& Akerson, V. (2003). Preservice teachers' development and implementation of science performance assessment tasks. (ERIC Document Reproduction Service No. ED 478065).

Mueller, J. (2012). The Authentic Assessment Toolbox: Enhancing student learning Through online Faculty Development. Journal of Online Learning and Teaching, 1(1).

Odeh, K. R. (2015). The Impact of Using Authentic Assessment on Ninth Grade Students Achievement and their Attitudes Towards Science in Nablus Governorate Schools. Unpublished Master Thesis, Al-Najah National University, Palestine

Ohlsen, M. T. (2007). Classroom assessment practices of secondary school members of NCTM. American Secondary Education, 36(1), 4-14.

Palestinian Ministry of Education and Higher Education (MoEHE). (2011). Results of Palestine students in TIMSS. Department of Measurement, Evaluation and Examinations, Ramallah, Palestine.

Lai, E. (2011). Performance-based Assessment: Some New Thoughts on an Old Idea. Bulletin, 20. Retrieved from http://www.pearsonassessments.com

Resnick, L. B. (1996). Performance puzzles: issues in measuring capabilities and certifying accomplishments. Los Angeles: CRESST/University of Pittsburgh, LRDC.

Read, J. (2008). Identifying academic language needs through Diagnostic Assessment. Journal of English for Academic Purposes, 7, 183-190. https://doi.org/10.1016/j.jeap.2008.02.001

Saadi, H. (2009). The effects of anxiety on students' achievement. The case of third year LMD students. Master Thesis, Mentrouri UniversityConstantine, Algeria. 
Scott, S. J. (2002). Using multiple methods of assessment to examine student achievement in Music. Retrieved from http://www.brandonu.ca/Music/People/FacultyPages/scotts/using_multiple_m ethods_of_assess.htm

Stiggins, R. J. (2001). Student-Involved Classroom Assessment (3rd ed.). Columbus OH: Merrill Education, an imprint of Prentice Hall.

Taylor, M. (2006). Generation Next Come to college: Updates and Emerging Issues. Self-Study and Institutional Improvement, 2, 48-55.

Volante, L. (2004). Teaching to the test: What every teacher and policy maker should know. Canadian Journal of Administration and Policy, 35(1), 1-6.

Whitman, C., Klagholz, L., Schechter, E., Doolan, J., \& Marganoff, B. (1998). New Jersy science curriculum framework. Retrieved from http://www.state.nj.us/njded/frameworks/science/

Zoubi, A. (2013). Knowledge and Utilization Degree of Authentic Assessment Strategies and Tools by Mathematical Teachers. IUG Journal of educational and Psychology Sciences, 21(3), 165-197.

\section{Copyrights}

Copyright for this article is retained by the author, with first publication rights granted to the journal.

This is an open-access article distributed under the terms and conditions of the Creative Commons Attribution license (http://creativecommons.org/licenses/by/4.0/). 